\title{
A bibliometric study on biomimetic and bioinspired membranes for water filtration
}

\author{
Gaurav Goel $\mathbb{D}^{1 凶}$, Claus Hélix-Nielsen $\mathbb{I D}^{2}$, Hari M. Upadhyaya ${ }^{1}$ and Saurav Goel $\mathbb{i D}^{1,3}$
}

Insights into the biological channels and synthetic pore-forming assemblies have elucidated many fundamental aspects of selective water and solute transport over the last few decades. This has led to the development of novel technologies with unique selectivity and permeability. In terms of membrane separation technology, this development has proceeded by adapting either of two approaches: (i) one where biological channel proteins are reconstituted in suitable materials mimicking the biological bilayer membrane and (ii) one where selective transport is mimicked in synthetic structures. The development of water filtration membranes in the former approach takes advantage of aquaporin proteins as representative building blocks and that of carbon nanotubes and molecular pore-forming assemblies in the latter approach. The first approach is often referred to as the field dominated by biomimetic membranes and the latter referred to as artificial water channels. In this study, a bibliometric analysis was conducted to investigate trends in these two areas based on growing publication trends, peer-reviewed journal selection, countries, institutions, authors, and collaborative networks. A total of 3199 records available from Scopus between 1962 and 2021 were extracted and analyzed. The results showed strong international collaborations and highlighted leading researchers and hubs of excellence in these two areas. This is very timely considering that the UN climate change conference (COP26) in Glasgow, UK later this year will bring focus to the global need for water treatment technologies. This work can serve as a quick reference for earlycareer researchers and industries working in the area of membrane development for water purification/filtration.

npj Clean Water (2021)4:41; https://doi.org/10.1038/s41545-021-00131-4

\section{INTRODUCTION}

The water, sanitation, and hygiene (WASH) sector is a key public health issue that is at the very core of the survival of people and is the focus of the first two targets of Sustainable Development Goal 6 (SDG 6) of the UN SDG charter. It not only addresses the issues relating to drinking water, sanitation, and hygiene, but also the quality and sustainability of water resources worldwide. About 3.6 billion people (close to half of the world's population) are living in areas with a potential water scarcity of one month per year and this scarcity is expected to span almost $4.8-5.7$ billion people by $2050^{1,2}$. Climate change, deforestation, farming with excessive use of fertilizers, urbanization, and the rising population are leading up to the problem of limited freshwater availability causing waterstressed conditions (see Fig. 1). This condition has been further exacerbated during the COVID-19 pandemic ${ }^{3}$. Alarmed by the need of safety concerns, people during this pandemic have been consuming more and more freshwater to clean themselves to maintain better hygiene. Limited availability of clean water has also resulted in the growth of the bottled water industry globally which has inherently led to a dramatic rise in plastic pollution caused by the mismanaged waste of plastic bottles. In this scenario, it becomes imperative to ensure and augment a sustainable supply of clean water.

The current demand for about $4600 \mathrm{~km}^{3}$ per year ${ }^{4}$ of clean water can only be met by recycling but its acceptance varies as per cultural and safety concerns ${ }^{5}$. Modern technologies are not reliable in ensuring cost-effective removal of contaminants during treatment and the emergence of various contaminants such as pharmaceuticals, personal care products, pesticides, herbicides, heavy metals as well as anti-microbial resistant bacteria has posed additional concerns ${ }^{6}$. Estradiol (E2) and Ethinyl estradiol (EE2) in surface water sources originating from consumption and excretion of oral contraceptive pills are few examples that cannot be removed efficiently by regular water treatment processes ${ }^{7,8}$. The presence of E2 and EE2 in water has been linked to depleting fish populations and intersex phenomena in freshwater fish ${ }^{9}$. Also, traces of pharmaceuticals including antibiotics, anticonvulsants, mood stabilizers, synthetic hormones, and oestrogens have been detected in drinking water supplies ${ }^{10,11}$. These and other studies establish that current water treatment facilities are facing serious challenges in tackling emerging contaminants.

Membrane technology is attracting increasing interest as part of water treatment technology. Depending on separation properties, membranes currently used in large-scale applications can be categorized into microfiltration (MF), ultrafiltration (UF), nanofiltration (NF), and reverse osmosis (RO), and all these are typically made from polymeric and ceramic materials (see Fig. 2).

Membranes are used in various fields including wastewater treatment, desalination, and drinking water treatment as well as in various medical applications such as artificial kidneys and artificial lungs ${ }^{12}$. However, membrane technology, especially RO is limited by high energy consumption and the need for pre-treatments, resulting in high operational expenses ${ }^{13}$. Also, despite the high selectivity in RO, the rejection of small nonpolar solutes is typically low ${ }^{14,15}$

Prevalent membrane manufacturing technologies are based on a 'top-down' macroscopic design approach which poses challenges in molecular selectivity of the material, defined as a measure of the permeability of the relevant compound for the membrane due to the non-uniform pore sizes. To improve this aspect, several 'bottom-up' strategies based on molecular designs have recently emerged. These are commonly referred to as

\footnotetext{
'School of Engineering, London South Bank University, London, UK. ²Department of Environmental Engineering, Technical University of Denmark, Kongens Lyngby, Denmark. ${ }^{3}$ Department of Mechanical Engineering, Shiv Nadar University, Gautam Budh Nagar, Greater Noida, India. ${ }^{凶}$ email: GoeLg@LSBU.ac.uk
} 
biomimetic or bioinspired membranes ${ }^{16}$. This field is rapidly developing and global events such as the 2018 Artificial Water Channels Faraday Discussions meeting ${ }^{17}$ have seen extensive discussions covering various fields including biology, physics, and chemistry. To gain more insights into this interesting direction of research, authoritative reviews are readily available ${ }^{18-20}$. Additionally, a review written by the authors of this paper providing clarity on the subtle differences between the terms bioinspiration and biomimetics is also now available ${ }^{21}$. Separate from these reviews, the scope of this paper is to provide a critical bibliometric analysis of the recent trends and developments in terms of leading researchers/groups and collaboration networks actively working in this direction of research.

\section{Bioinspired bottom-up design strategies}

Proteins and peptide-based structures can facilitate highly selective transport of water and ions across biological membranes, and this has inspired their use in allied technologies concerning separation principles and translating into new materials (see Fig. 3). Pioneering studies include transport in planar lipid bilayers ${ }^{22}$ and

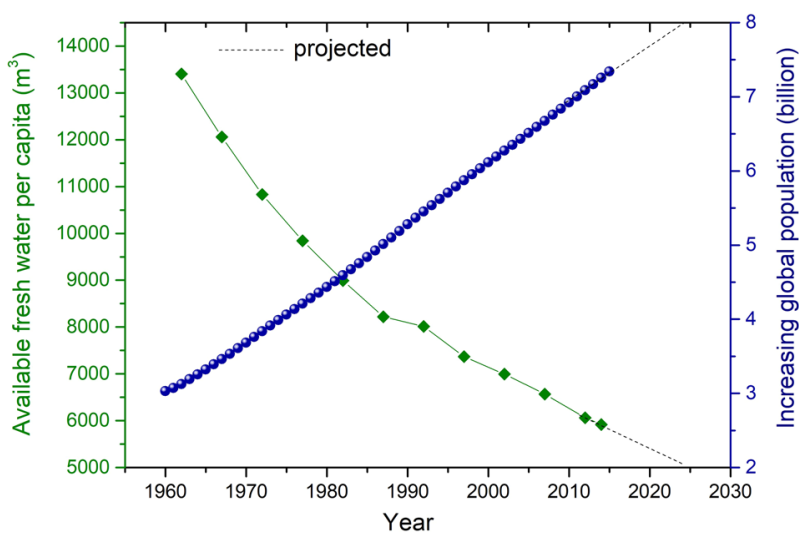

Fig. 1 Global trend. Reduced water availability and increasing population $^{85,86}$. the effect of ionophores (e.g., valinomycin, gramicidin, and nonactin $)^{23,24}$. Also, biomimetic energy conversion, using rhodopsin proteins, has been studied since the $1970 \mathrm{~s}^{25-28}$. However, a breakthrough came through the discovery of 'nature's water channel', the aquaporin protein ${ }^{29}$, which led to the award of the Nobel Prize to Peter Agre in $2003^{30,31}$. At present, most developments and research on biomimetic membrane technology are based on the use of aquaporin proteins ${ }^{18,32,33}$. The terms biomimetic membranes and aquaporin membranes have become almost synonymous and the technology is now gradually being commercialized $^{34}$. Besides water treatment and energy conversion, biomimetic membranes are also being explored for use in biomedicine, biosensor, and carbon capture technologies ${ }^{35,36}$.

\section{Membrane protein-mediated separation}

Aquaporin proteins (or aquaporins) are transmembrane-spanning proteins capable of facilitating water transport across cellular membranes. Certain aquaporin isoforms are highly selective to water and are also referred to as orthodox aquaporins. They have remarkably high-water permeability (up to $10^{9} \mathrm{H}_{2} \mathrm{O}$ molecules $\mathrm{s}^{-1}$ ) reflecting the low $\left(\sim 5 \mathrm{kcal} \mathrm{mol}^{-1}\right)$ energy barrier to transport ${ }^{35}$. Aquaporin proteins can be seen as building blocks for membrane design $^{35,37,38}$ and, in principle, one gram of aquaporin protein can filter up to $700 \mathrm{~L}$ of water per second. Compared to traditional polymeric membranes this translates into a 10-100 fold higher productivity $\left(\mathrm{m} \mathrm{s}^{-1} \mathrm{bar}^{-1}\right)^{39}$.

In particular, the $E$. coli bacterial isoform AqpZ is a comparably stable orthodox aquaporin ${ }^{40,41}$ and is mostly explored in the development of biomimetic water purification technology. The AqpZ water channel is narrow $(\sim 2.3 \AA)$ which allows for single-file transport of water molecules while preventing passage of other solutes ${ }^{42}$. The selectivity mechanism is based on size exclusion, electrostatic repulsion, and water molecule dipole reorientation ${ }^{43}$. The fast transport of water through aquaporin channels can be described as a "frictionless" non-Poiseuille flow (slip flow) via a smooth narrow hydrophobic channel ${ }^{44}$ as opposed to the frictioninduced flow through carbon nanotubes (CNTs) ${ }^{45}$.

Due to the obvious potentials of the aquaporin technology, NASA (USA) is actively investigating the possibility of using

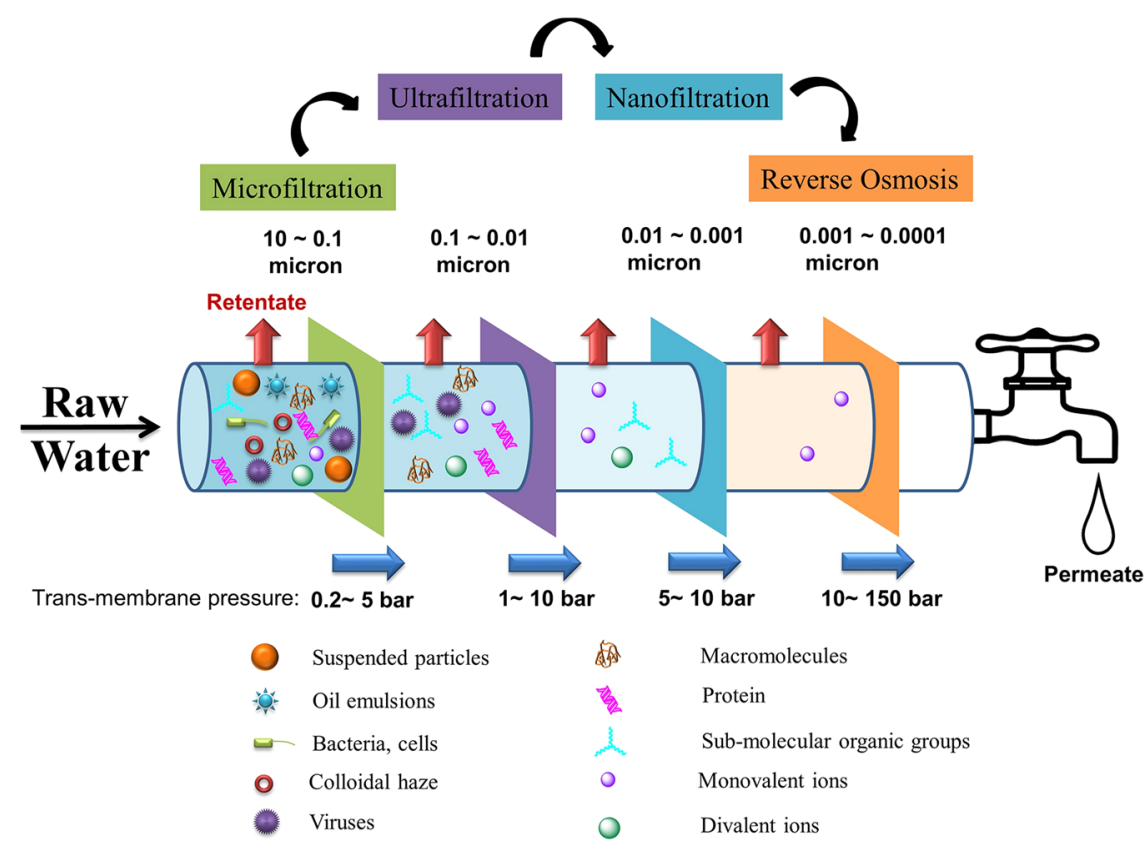

Fig. 2 Basic features of commonly used water treatment membrane. Membranes are typically made from polymeric and ceramic materials. Reproduced with permission from ref. ${ }^{87}$, copyright (Elsevier, 2018). 


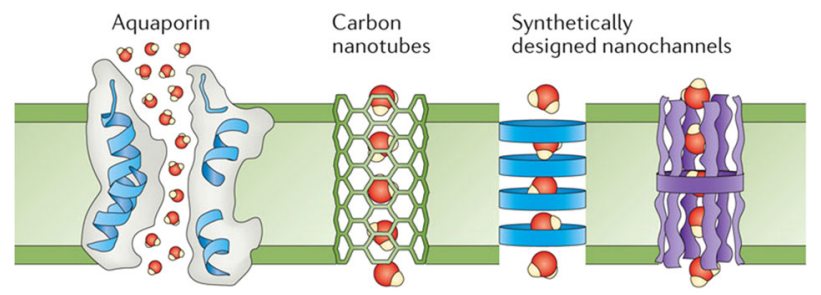

Fig. 3 Examples of biomimetic and bioinspired membrane. Membrane materials as water selective building blocks in form of (left) aquaporin proteins (AQPs), (centre) carbon nanotubes (CNTs), and (right) molecular pore-forming assemblies. Reproduced with permission from ref. ${ }^{15}$, copyright (Springer Nature, 2016).

biomimetic membranes in space missions ${ }^{46,47}$. Also, biomimetic membranes are now being used commercially in applications ranging from food and beverage processing, wastewater treatment, and industrial water reuse ${ }^{34}$. However, full-scale implementation of biomimetic aquaporin membranes is still in its infancy ${ }^{48,49}$. Recently, the fabrication of two-dimensional crystalline sheets with a high packing density of $\beta$-barrel structure channels has been demonstrated which may pave the way for increasing the membrane performance in terms of flux and rejection ${ }^{32}$.

\section{De novo design of water selective materials}

The development of artificial water channels as building blocks for separation membranes was initiated by the seminal molecular dynamics (MD) simulations paper by Hummer et al. $^{50}$ revealing water transport through sub-nm diameter carbon nanotubes (CNTs). Five years later, the first experimental realization of a CNTbased membrane was published, albeit, not with sub-nm tubes ${ }^{51}$. Recently, highly permeable (up to 6-fold higher than in the mammalian orthodox AQP1) $0.8 \mathrm{~nm}$ diameter CNTs embedded in a lipid membrane matrix were reported where the transport mechanism is based on a single-file water molecule transport ${ }^{52}$. However, these CNTs are also permeable to cations $\left(\mathrm{K}^{+}\right.$and $\left.\mathrm{H}^{+}\right)$. A good discussion on CNT water permeation and ionic selectivity can be found in a paper by Corry ${ }^{53}$.

In parallel to the focus on CNTs, several research groups have worked with multi-molecular self-assembled structures. For instance, helical hydrophobic pores built from self-assembly of dendritic dipeptides are seen capable of water and proton transport with the rejection of other cations and anions ${ }^{54}$. Also, the so-called imidazole (I) quartets stabilized by inner dipolar water wires can form chiral self-assembled narrow $(<0.3 \mathrm{~nm})$ channel structures with high water permeability ${ }^{55,56}$. Recently, hybrid polyamide membranes with embedded I-quartets have shown highly selective transport of water with $99.5 \%$ screening of $\mathrm{NaCl}$ and $91.4 \%$ screening of boron, with a water flux of $75 \mathrm{I} \mathrm{m}^{-2}$ $\mathrm{h}^{-1}$ at 65 bar using a feed solution representative of seawater ${ }^{57}$. Self-assembling water-permeable channels can also be built from stacks of m-oligophenylethynyl (OPE) macrocycles stabilized by $\mathrm{H}$ bonding networks and aromatic backbone stacking between the macrocyclic. These channels have significant water permeability, albeit, five-fold lower than AQP1. They also have finite ionic permeability $(<6 \mathrm{pS})$ for $\mathrm{K}^{+}$but are impermeable to $\mathrm{Na}^{+58}$. The latest study has demonstrated 2.5 times water permeability than that of AQP1 with foldamer-based artificial water channels ${ }^{59}$.

Single and bimolecular molecular water (and $\left.\mathrm{OH}^{-}\right)$channels can be formed from Pillar[5]arene derivatives with attached oligohydrazide chains stabilized by intramolecular $\mathrm{H}$-bonds in a bilayer membrane ${ }^{60}$. These channels have no apparent $\mathrm{H}^{+}$transport which may be explained via alternative hydrophobic/hydrophilic lumen regions disrupting water wires formation akin to the mechanism found in orthodox aquaporins (e.g., AqpZ and AQP1) although they can sustain transport of cations to some degree. Most recent studies on this have shown improved selectivity ${ }^{61-63}$.

In summary, the research field of artificial water channels is still a fertile area of research and despite numerous advances made during the last two decades; there are major outstanding challenges where stabilization of the molecular complexes and ensuring efficient selectivity properties are among the pertinent challenges. Recent reviews may be referred for further details ${ }^{64,65}$.

\section{BIBLIOMETRIC ANALYSIS}

To the best of our knowledge, there are no bibliometric studies on biomimetic membrane development. This study aims to survey the publications and research trends in biomimetic membranes based on the publicly available scientific literature database using scientometric analysis.

Bibliometric analysis is a strong tool for understanding the growth and prospects of a research area. Bibliometric strategies have been utilized to examine the evolution of research fields, recognize associations between logical development and strategy changes and identify the growing interdisciplinary collaborations ${ }^{66}$. The bibliometric analysis offers in-depth quantitative and statistical scientific insights into the methods for making decisions about policy matters. For example, the British government initiated a pilot project to make bibliometric analysis a part of the research excellence framework (REF) to decide the university funding strategies ${ }^{67}$. An early example is the study of Pritchard ${ }^{68}$ and over the last three decades, bibliometric analyses have benefitted from the advent of the world wide web. Now comprehensive analyses can be performed using various online databases (e.g., Scopus, Google Scholar, and Web of Science). In addition, various software tools such as Citespace, Bibexcel, Publish or Perish, Ucinet, Gephi, Pajek, VOSviewer, and Science of Science $\left(\mathrm{Sci}^{2}\right)$ can provide illustrative data representation and mapping $^{69}$.

Scopus, a database containing $>70$ million entries from more than 5000 publishers with records dating back to 1788 is the most reliable database for bibliometric investigations especially because each record is labelled with key data such as author's name, source, referred-to references, catchphrases, publisher, publication date and research area. Furthermore, clients can download the total metadata for entries in a particular research field based on a given inquiry term. Visualization of similarity (VOS) mapping is a topical-based procedure that permits representative and clear conception of progressively research fields ${ }^{70}$. Also, VOS mapping can outline clusters and collaboration networks with vortices connected by edges ${ }^{66,71}$. Edges in the graph are based on direct citations. Vortices are assigned based on weight (e.g., number of publications) and score (e.g., citations per journal or country) with equal weightage assigned to these factors. Clusters are defined from bibliographic coupling (i.e., if paper $A$ is cited by papers $B, C$ and $D$ then the respective paper pairs $(B$ and $C, B$ and $D$, and $C$ and D) form a cluster relationship ${ }^{72}$.

Here we combine network, cluster, and bibliometric analyses of scientific literature metadata within the area of biomimetic and bioinspired membranes. Specifically, we address eight key questions: (i) How many peer-reviewed publications are available on the topic of biomimetic membranes and artificial water channels for membranes and what is their growth trend? (ii) What are the major scientific and technological areas covered within this research? (iii) Which are the most cited publications? (iv) Which journals are the most active outlets for this type of research? (v) Which scientific institutions are leading this area of research? (vi) Which countries are focused on supporting growth in this area? (vii) Who are the leading authors and who is collaborating with who? and (viii) What sort of developments have shaped the advances in this area? 


\section{Data gathering and methods}

In this investigation, comprehensive research was carried out by analyzing the literature available from Scopus from January 1962 to March 2021. To identify the patterns, both bibliometric investigations and structural approaches were used. The total metadata of all scientific publications was collated in MS Excel format. The query keywords used for this topical analysis were biomimetic membranes water and artificial water channels. In selecting search keywords, a certain degree of overlap is unavoidable i.e., a particular publication can overlap both in the biomimetic membrane water and artificial water channels keyword search, but the overlap was less than $2 \%$. Also, some of the biomimetic membranes may contain records that do not per se address water purification. Nevertheless, we believe that we capture the overall pattern using the selected keywords.

We used VOSviewer (version 1.6.15) to construct and visualize bibliometric networks in terms of publication networks and collaboration networks quantified as publications citing other publications $^{73}$. The Bibliometrix (version 3.0) R package was used for bibliometric analysis of metadata from Scopus for calculating the overall collaboration index ${ }^{74}$.

\section{TRENDS IN SCIENTIFIC STUDIES ON BIOMIMETIC MEMBRANES}

A total of 2865 entries were found most relevant after the screening of the entire data based on the papers published in the English language. The record distributions were divided into five classes: original research papers $(2133 ; 75 \%)$, review papers (267; $9 \%)$, conference papers (170; 6\%), book chapters $(43 ; 2 \%)$, and others such as book, letter, erratum etc. (252; 8\%). 398 of these entries were 'open access' (14\%) and the remaining were available through subscription. The average number of citations per paper was 11.25 and the average number of authors per paper was 3.68 with $(75 ; 3 \%)$ being single-author papers. The overall collaboration index calculated as the total number of authors of multi-authored articles divided by the total number of multi-authored articles was 3.8.

\section{Number of publications on biomimetic membranes since $\mathbf{2 0 0 0}$}

Figure 4 shows the growth trend in biomimetic membranes over the last two decades. Prior to 2000, very few papers were published in this area. More than $76 \%$ of the publications were published after 2009. The entire period (1962-2021) can roughly be divided into two periods: an early explorative phase until 2002 and a developmental phase from 2003 onwards.

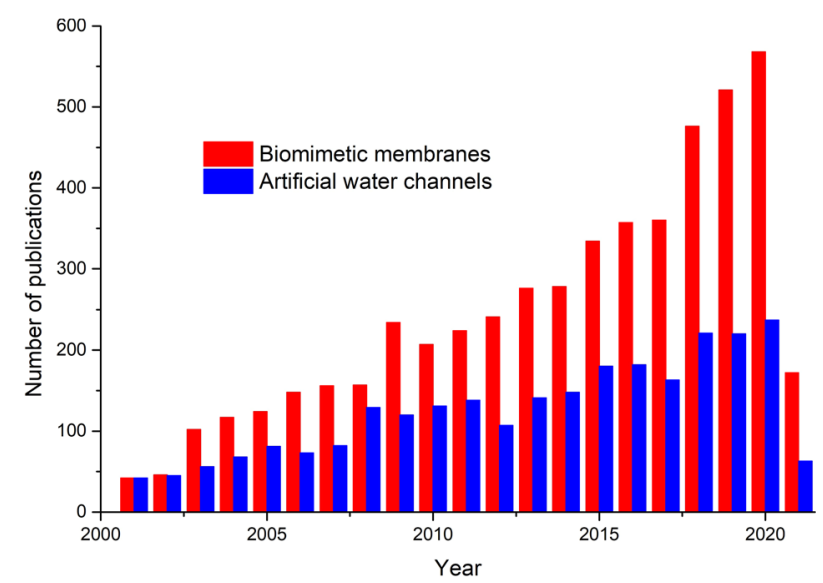

Fig. 4 Number of publications per year from January 2000 to March 2021. Publications for biomimetic membranes and artificial water channels.
During the early phase, biomimetic membrane development was mainly focused on ionophore-based ion-selective electrodes, and efforts were directed towards energy harvesting (e.g., artificial photosynthesis). The developmental phase started after the first crystal structure of aquaporin was reported in $2000^{75}$. This and subsequent structures reported in the following years enabled a detailed molecular understanding of the transport mechanisms which in turn spurred a growing interest in the biomimetic membrane research area.

From 2003 to 2012, the number of scientific publications showed an average annual growth rate of $7 \%$. During this period, more crystal structures of aquaporins became available, and more atomistic simulations appeared elucidating transport mechanisms in narrow conduits. In 2004-2005, the first aquaporin membrane patent application was filed ${ }^{76,77}$ and in 2007, it was demonstrated how aquaporin proteins can be incorporated into polymeric vesicles $^{39}$. Still, the challenge was to create large-scale synthetic biomimetic membranes ${ }^{78,79}$. During this time, forward osmosis (FO) became a commercial technology pioneered by Hydration Technology Innovations (HTI) ${ }^{66,80}$. Companies such as Oasys Water, Modern Water, Porifera, Trevi Systems, Applied Biomimetic, and Aquaporin A/S also emerged in the FO market ${ }^{48}$. FO may be considered as a biomimetic process (as biological water transport is partly mediated by aquaporins) but not a biomimetic product as such-still FO as a technology may indeed have spurred interest in the scientific understanding of the molecular basis for selective efficient water transport.

From 2012 onwards, the average annual percentage growth of the number of publications rose to $15 \%$ and from 2018, an average of 500 publications are being published annually consolidating the field as an established research area. In parallel, technological developments are ongoing as exemplified by the Danish company Aquaporin A/S which from 2012 began commercializing biomimetic aquaporin $\mathrm{FO}$ and RO membranes based on joint research collaboration with Singapore Membrane Technology Centre ${ }^{81}$. Aquaporin now makes products for various industrial applications ${ }^{82-84}$.

Figure 4 also highlights increasing research in artificial water channels measured by the number of publications. Interest in this area grew from 2000 and peaked around 2010 with a subsequent stabilization in the publication activity. Despite the concomitant commercial realization of aquaporin biomimetic membranes, it is clear that protein-based membrane designs are still facing significant challenges such as ensuring a sufficiently high density of aquaporins in the membrane material to make full use of the water transport potential. These challenges are likely to continue to spur interest in artificial water channel research.

\section{Major disciplines and leading journals for biomimetic membranes research}

The major disciplines reporting research on biomimetic membranes are shown in Fig. 5. From a Scopus search, 21 disciplines were identified and the top six disciplines each having more than 500 publications are shown here. Publications on artificial water channels for the same categories selected are also shown. Some of these publications may have happened in several disciplines because of the topic and shared co-authorship.

For papers classified as biomimetic membranes, most were published within the materials science category with the lowest number of publications in the environmental science category. For papers classified as artificial water channels, this pattern reverses with most papers published within the environmental science category and the lowest number in the materials science category. This may reflect the earlier onset of interest in biomimetic membranes with a strong focus on creating a new membrane material per se. The annual publications reached 25 by 2003 for biomimetic membranes and this occurred five years later for 
artificial water channel papers. This reflects on a transition from an earlier technology-driven focus to a more challenge-driven focus in applications within environmental science.

This trend is also seen in the choice of journals for the two topics (see Table 1). For the biomimetic membrane publications, a significant body is published in journals with a biological/ biophysical scope reflecting the focus on biological proteins within the topic. For artificial channels journals, scopes generally fall within a broader technology focus. The analysis also shows that the top ten journals account for only $15 \%$ of publications reflecting a high diversity in the choice of journal. The Scopus CiteScore values (i.e., the average citations received by the publications in that particular journal) fall within a wide range for both topic classes.

To analyze the citations, mapping plots were made for the top 25 journals in terms of papers published using VOSviewer (see Fig. 6). Network connections were derived based on the citations of a given paper in a particular journal by papers published in other journals.

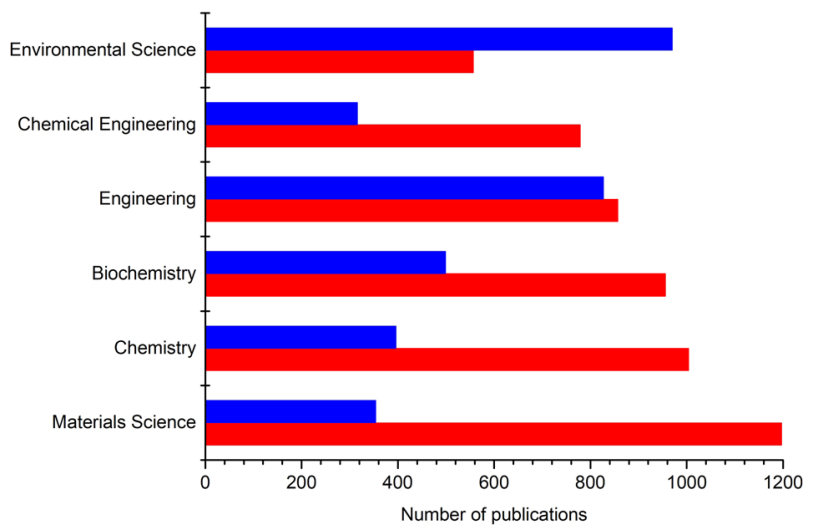

Fig. 5 Publications within the top six disciplines. Publications on the topic of biomimetic membranes (red colour) and on artificial water channels (blue colour).
Before 2010, the choice of main journals for biomimetic membranes was characterized by 'biology'-type journals with strong network connections. Later, more recently broader scoped journals emerged, and the maturity of the field is evident from papers published in the leading technology journal Journal of Membrane Science over the years. For artificial water channels papers, the analysis revealed a more distributed network but with the Journal of Membrane Science appearing as the main choice.

\section{Highly cited reviews and research papers}

Tables 2 and 3 show the top 10 highly cited research papers in biomimetic membranes and artificial water channels respectively during the considered period. A list of the top 20 cited review papers for both classes is presented in Table 4 . These review papers cover a wide spectrum of ideas and processes related to biomimetic membranes synthesis and applications. Initially, the main focus was on applications in biomedicine, biosensors, and energy conversion. However medical applications, sensor sensitivity, and energy conversion remain a biomimetic challenge in terms of up-scaling and efficiency. A spike occurred after 2010 with focus leaning towards separation applications paving the way for full-scale disruptive technologies and applications. Table 5 provide details of review papers published after 2019. The fact that 14 papers were published in such a short time testified growing interest in separation processes.

\section{Leading countries and organizations}

The leading countries in biomimetic membranes and artificial water channels research are shown in Fig. 7 respectively. More than $99 \%$ of the papers are multi-authored; hence multiple countries may get registered for a given entry.

For the biomimetic membrane topic, the USA and China are leading the list in terms of the number of publications. The top 10 countries account for more than $80 \%$ of the publications in this area. When analyzing the normalized share of publications calculated as the ratio between the number of publications and

\begin{tabular}{|c|c|c|c|c|c|}
\hline \multirow[t]{7}{*}{ Biomimetic membranes } & 1 & Langmuir & 6.1 & 174 & 3.6 \\
\hline & 3 & Journal of the American Chemical Society & 24.8 & 99 & 2.0 \\
\hline & 4 & ACS Applied Materials and Interfaces & 13.6 & 81 & 1.7 \\
\hline & 7 & Journal of membrane science & 12.3 & 60 & 1.2 \\
\hline & 8 & Colloids and Surfaces B: Biointerfaces & 7.1 & 55 & 1.1 \\
\hline & 9 & Advanced Functional Materials & 22.0 & 51 & 1.0 \\
\hline & 10 & Angewandte Chemie - International Edition & 20.8 & 48 & 1.0 \\
\hline \multirow[t]{7}{*}{ Artificial water channels } & 1 & Journal of Membrane Science & 12.3 & 23 & 5.5 \\
\hline & 5 & Water Science and Technology & 2.9 & 8 & 1.9 \\
\hline & 6 & Journal of Hydraulic Engineering & 3.9 & 7 & 1.7 \\
\hline & 7 & Journal of the American Chemical Society & 24.8 & 7 & 1.7 \\
\hline & 8 & Analytical Chemistry & 10.5 & 5 & 1.2 \\
\hline & 9 & Angewandte Chemie - International Edition & 20.8 & 5 & 1.2 \\
\hline & 10 & Hydrological Processes & 6.2 & 5 & 1.2 \\
\hline
\end{tabular}


a)

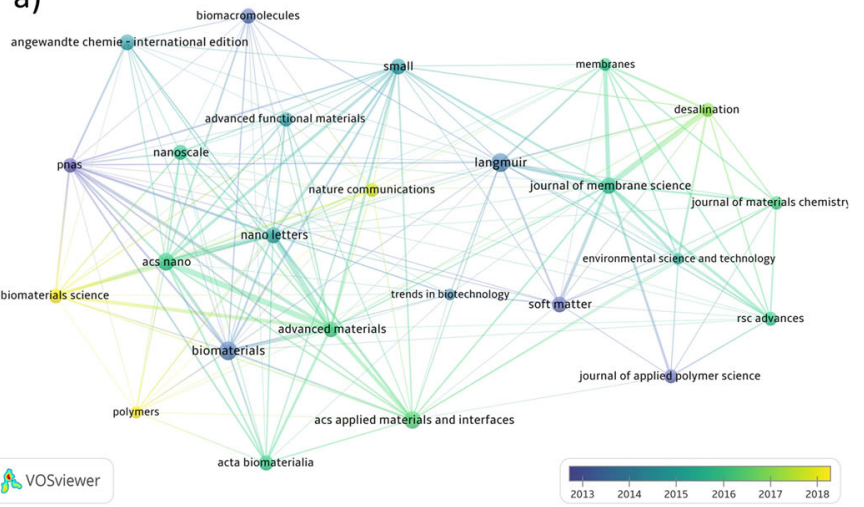

b)

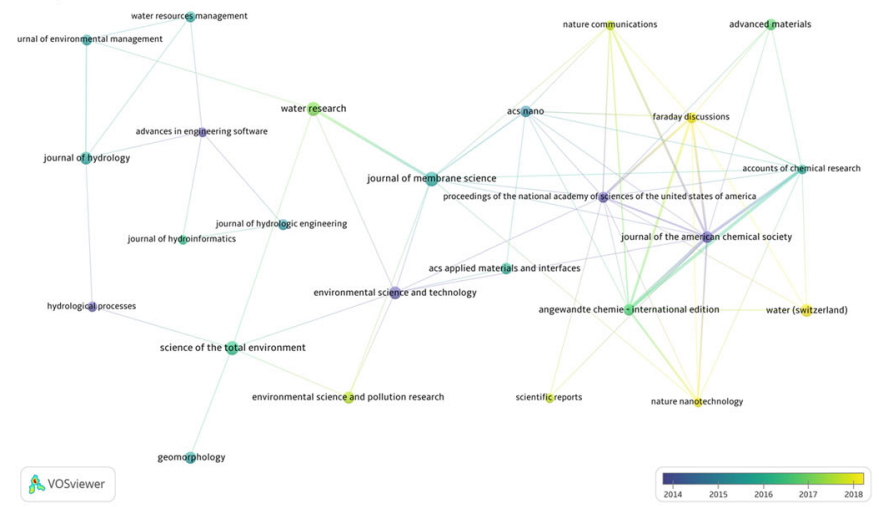

Fig. 6 Publication network for the top 25 journals. Publications for papers on (a) biomimetic membranes and for (b) artificial water channel publications.

Table 2. Top 10 highly cited papers on biomimetic membranes.

Rank Title

Year Reference

1 Synthesis of robust and high-performance aquaporin-based biomimetic membranes by interfacial polymerization-

201281 membrane preparation and RO performance characterization

2 Optimizing water permeability through the hourglass shape of aquaporins

201388

Aquaporin-embedded biomimetic membranes for nanofiltration

Preparation of high-performance nanofiltration (NF) membranes incorporated with aquaporin Z

201289

An aquaporin-based vesicle-embedded polymeric membrane for low energy water filtration

201490

Nature gives the best solution for desalination: aquaporin-based hollow fibre composite membrane with superior

201391 performance

201592

Layer-by-layer assembly of aquaporin z-incorporated biomimetic membranes for water purification

201593

Preparation of supported lipid membranes for aquaporin $\mathrm{Z}$ incorporation

201294

Aquaporin-based biomimetic reverse osmosis membranes: stability and long term performance

201695

10 Planar biomimetic aquaporin-incorporated triblock copolymer membranes on porous alumina support for nanofiltration

201296

Table 3. Top 10 highly cited papers on artificial water channels.

\begin{tabular}{|c|c|c|c|}
\hline Rank & Title & Year & Reference \\
\hline 1 & Single-molecular artificial transmembrane water channels & 2012 & 60 \\
\hline 2 & Selective artificial transmembrane channels for protons by the formation of water wires & 2011 & 97 \\
\hline 3 & Ultraporous films with uniform nanochannels by block copolymer micelles assembly & 2010 & 98 \\
\hline 4 & Self-organized liquid-crystalline nanostructured membranes for water treatment: selective permeation of ions & 2012 & 99 \\
\hline 5 & Mass transport through carbon nanotube membranes in three different regimes: ionic diffusion and gas and liquid flow & 2011 & 100 \\
\hline 6 & Fast mass transport through Sub-2-nanometre carbon nanotubes & 2006 & 51 \\
\hline 7 & Highly permeable artificial water channels that can self-assemble into two-dimensional arrays & 2015 & 101 \\
\hline 8 & Control performance and biomembrane disturbance of carbon nanotube artificial water channels by nitrogen-doping & 2010 & 102 \\
\hline 9 & Molecular transport through capillaries made with atomic-scale precision & 2016 & 103 \\
\hline 10 & Creating nanocavities of tunable sizes: hollow helices & 2002 & 104 \\
\hline
\end{tabular}

population of the country, Singapore and Denmark stand out in terms of research intensity on biomimetic membranes. For Singapore, this reflects a strong governmental focus in terms of research funding (e.g., to Nanyang Technological University and the National University of Singapore) and for Denmark, this reflects the commercial activities driven by the Danish company Aquaporin A/S and engineering activities led primarily at the Technical University of Denmark. For artificial water channels again the USA and China are leading in terms of the number of publications. The top 10 countries account for more than $74 \%$ of publications in this area. In terms of the normalized share of publications, Australia is leading followed by Canada, and several European countries including France, the United Kingdom, and Germany.

The author's collaboration networks indicate the development taking place in a multi-institutional and multinational manner 
Table 4. Top 20 cited review papers on biomimetic membrane and artificial water channels.

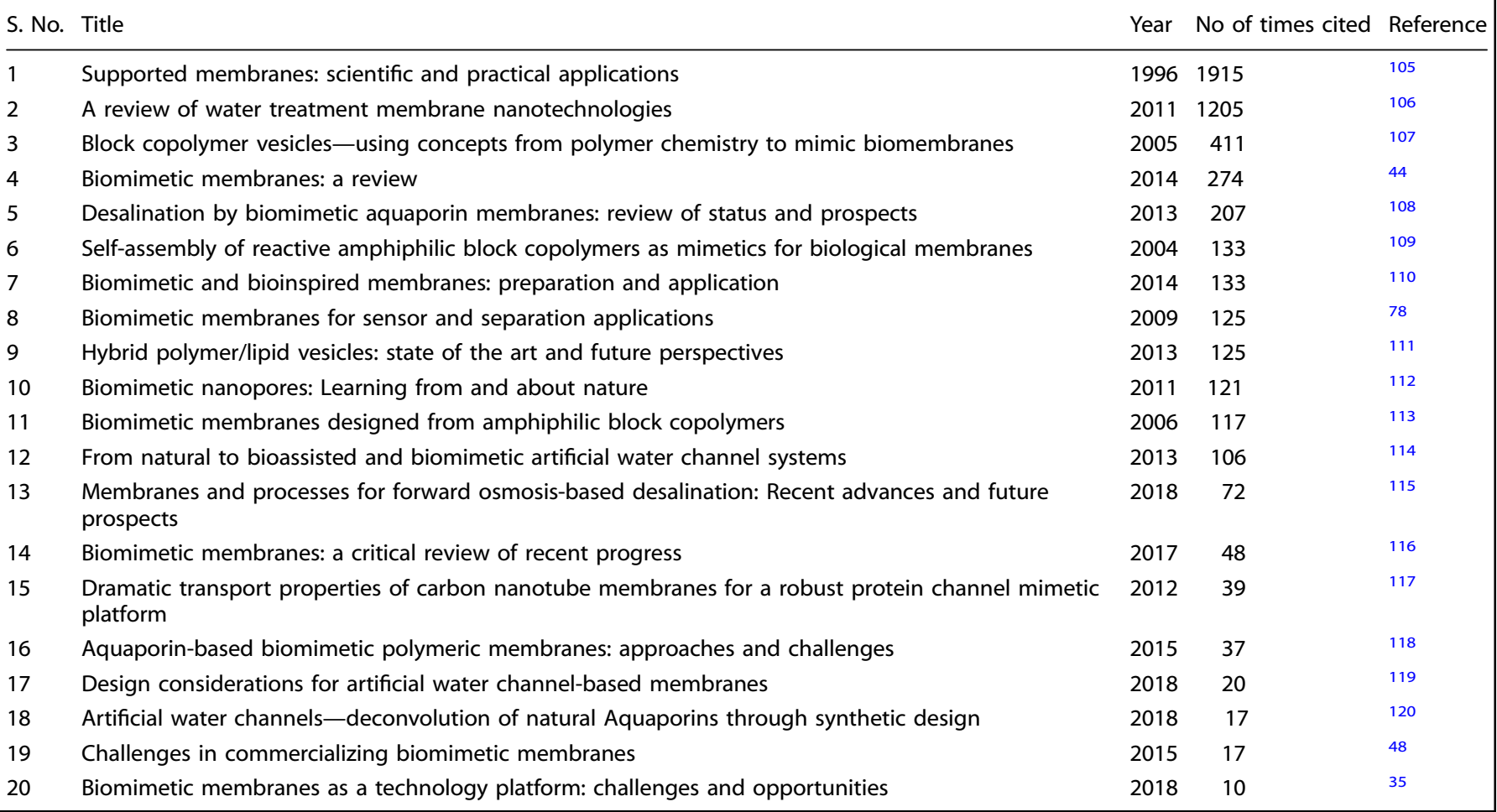

Table 5. Recent review papers from 2019 on biomimetic membrane and artificial water channels.

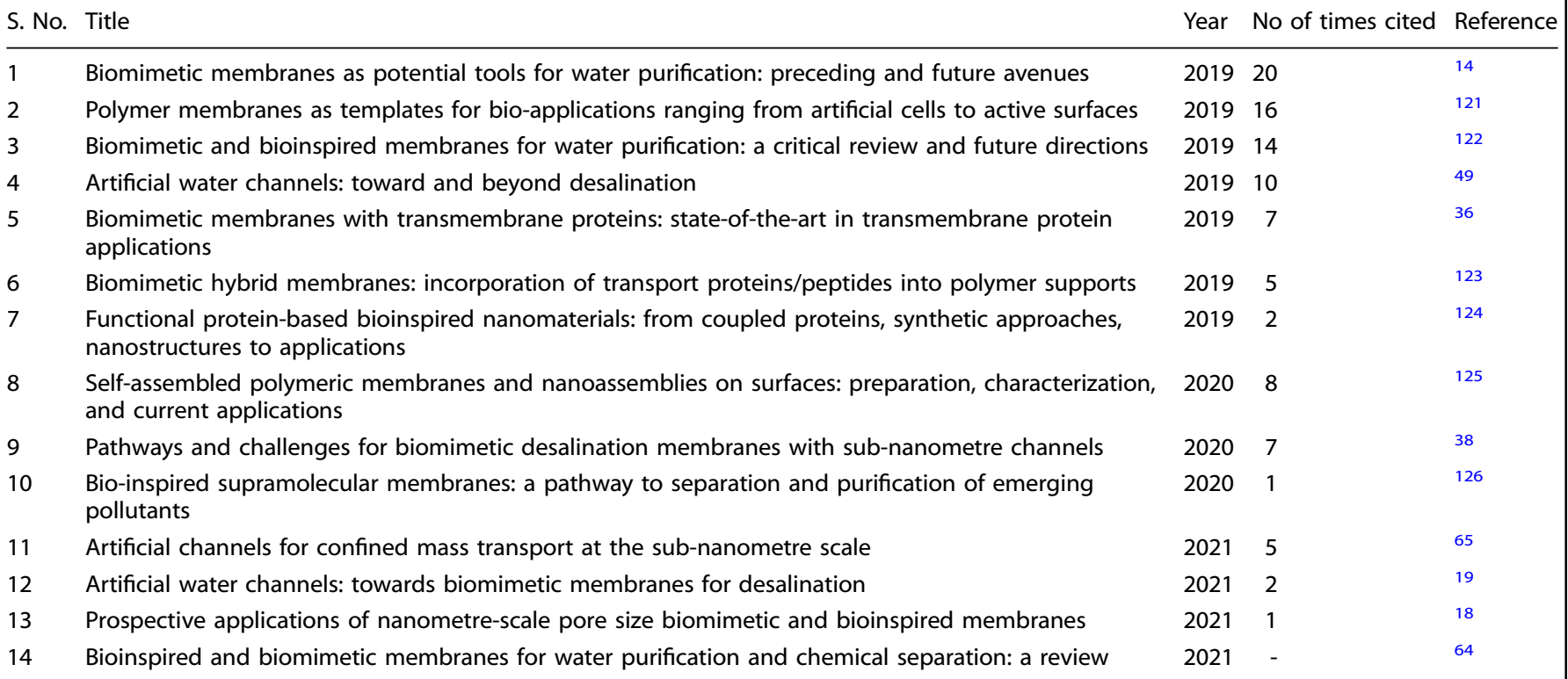

taking advantage of infrastructures available in author institutions and countries, see Fig. 8. For biomimetic membranes three clusters appear, a leading cluster (blue) dominated by the USA and China with contributions from Australia, Japan, and South Korea; a cluster (red) dominated by Germany, France, and the UK with contributions; and a cluster (green) with Singapore, Denmark, Sweden, India, and Slovenia. For artificial water channels, five clusters appear where the clusters are more equal in strength as compared to the area of the biomimetic membrane: a cluster with the USA and Brazil; a cluster (green) consisting of China, France, Japan, and Romania; a cluster (red) including Singapore and the UK. Russia, India, Canada, Iran, and Turkey; a cluster (blue) including Germany and Netherlands, Australia and Saudi Arabia and a cluster (yellow) with South Korea, Italy, and Sweden.

Table 6 shows the top 10 leading research institutions in terms of the number of publications where resources have been dedicated to research biomimetic membranes and artificial water channels. Three leading organizations are from China which 
a)

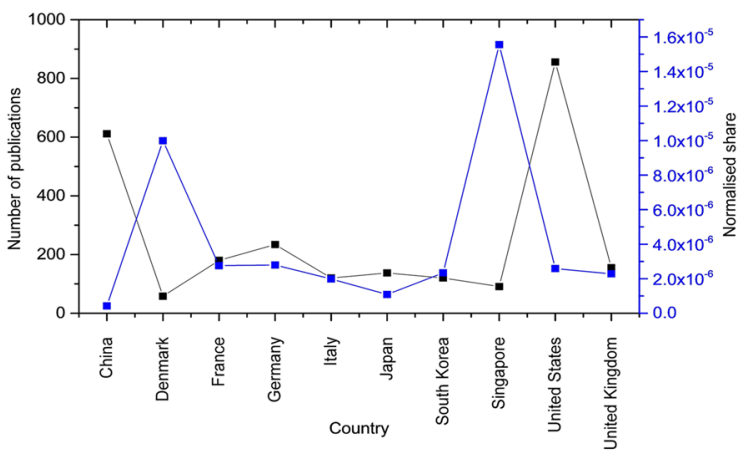

b)

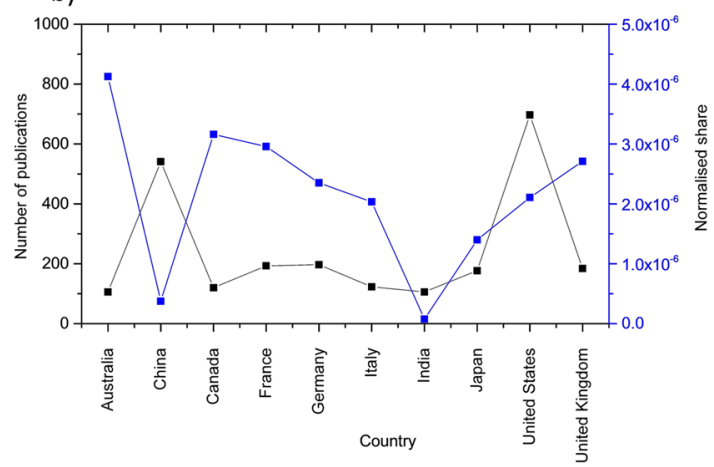

Fig. 7 Leading countries for publications in terms of the number of publications. Publications in terms of the number of publications (black) and normalized share (blue) $\mathbf{a}$ biomimetic membranes and $\mathbf{b}$ artificial water channels.

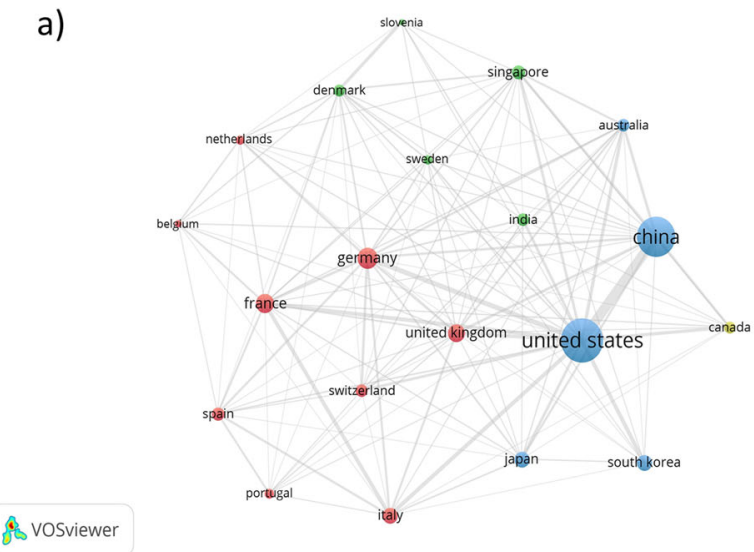

Cluster $1 \bigcirc$ Cluster $2 \bigcirc$ Cluster 3

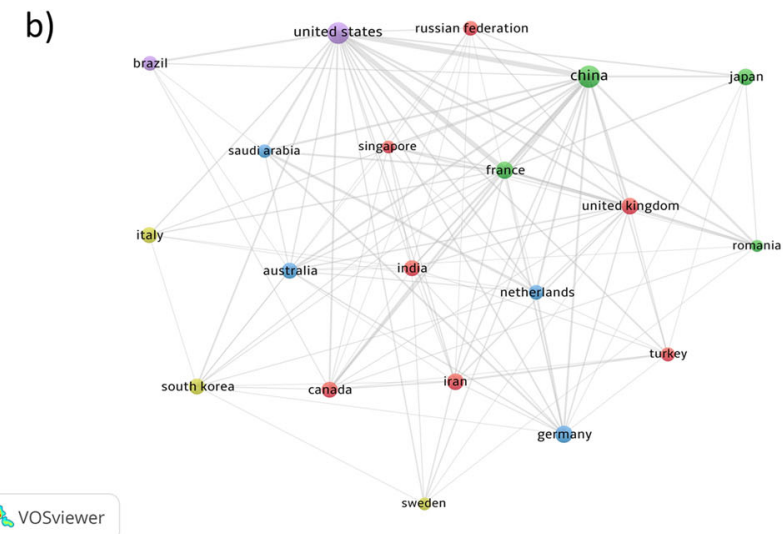

Cluster $1 \bigcirc$ Cluster $2 \bigcirc$ Cluster $3 \bigcirc$ Cluster $4 \bigcirc$ Cluster 5

Fig. 8 Collaboration network between top 20 productive countries. Collaboration network in terms of the number of biomimetic membrane publications (a), and the number of artificial water channel publications (b).

indicates a strong research focus in these two areas. Although the USA is leading in terms of the number of biomimetic membrane publications (Fig. 7), only one institution: University of California, San Diego is featured in Table 6 (entry 4 in Table 6) reflecting that research in the area is distributed among many institutions. Similarly, for artificial water channels, only Pennsylvania State University from the USA is featured in Table 6.

\section{Leading authors and their networks}

The leading authors who have contributed to biomimetic membranes and artificial water channels are listed in Tables 7 and 8 respectively. For biomimetic membranes, these author's main research topics as judged from their publications fall primarily within biochemistry and biophysics and to a lesser extent within environmental science. This reflects the findings in Fig. 5b, where materials science, biochemistry, and chemistry are prominent categories. The underlying reason behind this pattern is likely linked to the long history of research in biological membranes focusing on physiological and physical-chemical properties. The discovery of aquaporins originated from this research and led to the subsequent translation into technology development. For artificial water channels, the focus areas are dominated by biophysics, materials science, and research in separation technology and water treatment consistent with the findings in Fig. $5 b$.

\section{CONCLUSIONS AND OUTLOOK}

The last two decades have witnessed tumultuous interest in developing new membrane materials for use in water separation and purification technologies. Previous developments of water treatment membranes have been dominated by a top-down approach exemplified by the thin-film composite membrane design where separation properties originate from meso- and macro-scale bulk material properties. With an improved understanding of how water and solutes interact at the nanoscale, membranes can now be designed with a bottom-up strategy by employing naturally occurring or synthesized sub-nanometre porous structures. The bibliometric analysis presented in this paper shows that the biomimetic bottom-up approach has accelerated since 2003, with the average annual number of publications on this topic now exceeding 200. The bottom-up approach based on synthetic nano-scale materials took off around 2007 with a lower volume in terms of the number of publications. Concerning journals, the biomimetic membrane area is dominated by 'biology scope' journals whereas, for artificial water channels, the journal list is broader. Research within the biomimetic membrane and artificial water channels can be characterized by strong international collaborations. In terms of the absolute number of publications, the USA and China are currently leading. Normalized by the country population size, Singapore and Denmark have significant activities in the biomimetic membrane area and Australia, Canada, France, and the UK have significant activities in the artificial water channel area. Recent reviews 


\begin{tabular}{|c|c|c|c|c|}
\hline \multirow[t]{8}{*}{ Biomimetic membrane } & 1 & Ministry of Education China & China & 275 \\
\hline & 2 & Chinese Academy of Sciences & China & 237 \\
\hline & 3 & CNRS Centre National de la Recherche Scientifique & France & 165 \\
\hline & 4 & University of California, San Diego & USA & 135 \\
\hline & 7 & Nanyang Technological University & Singapore & 63 \\
\hline & 8 & Sorbonne Universite & France & 56 \\
\hline & 9 & Max Planck Institute of Colloids and Interfaces & Germany & 51 \\
\hline & 10 & Technical University of Denmark & Denmark & 48 \\
\hline \multirow[t]{7}{*}{ Artificial water channels } & 1 & Chinese Academy of Sciences & China & 90 \\
\hline & 5 & Tsinghua University & China & 30 \\
\hline & 6 & Consiglio Nazionale delle Ricerche & Italy & 27 \\
\hline & 7 & Université de Montpellier & France & 27 \\
\hline & 8 & Pennsylvania State University & USA & 26 \\
\hline & 9 & Institut Européen des Membranes UMR5635 & France & 26 \\
\hline & 10 & Russian Academy of Sciences & Russia & 25 \\
\hline
\end{tabular}

Table 7. Top 10 leading authors of biomimetic membranes publications.

\begin{tabular}{llllll}
\hline Rank & Author & Country & Organization & No of papers & Area \\
\hline 1 & Claus Hélix-Nielsen & Denmark & Technical University of Denmark & 24 & Environmental science \\
2 & Rong Wang & Singapore & Nanyang Technological University & 16 & Chemical engineering \\
3 & Taishung Chung & Singapore & National University of Singapore & 12 & Materials science \\
4 & A. G. Fane & Australia & The University of New South Wales Sydney & 11 & Chemical engineering \\
5 & Jaume Torres & Singapore & Nanyang Technological University & 11 & Biochemistry \\
6 & Arunmozhiarasi Armugam & Singapore & A-Star, Institute of Bioengineering and Nanotechnology & 10 & Biochemistry \\
7 & Kandiah Jeyaseelan & Singapore & National University of Singapore & 10 & Biochemistry \\
8 & Uwe Bernd Sleytr & Austria & Universitat fur Bodenkultur Wien & 9 & Materials science \\
9 & Yen Wah Tong & Singapore & National University of Singapore & 9 & Environmental science \\
10 & Xuesong Li & China & Tongji University & 8 & Environmental science \\
\hline
\end{tabular}

Table 8. Top 10 leading authors of artificial water channels publications.

\begin{tabular}{llllll}
\hline Rank & Author & Country & Organization & No of papers & Area \\
\hline 1 & Mihail D.Bărboiu & France & University of Montpellier & 26 & Biophysics/water treatment \\
2 & Manish Kumar & USA & The University of Texas at Austin & 21 & Separation technology \\
3 & Woochul Song & USA & The University of Texas at Austin & 11 & Biomedicine/separation \\
4 & Lei Jiang & Australia & Monash University, Melbourne & 10 & Material science \\
5 & Yuexiao Shen & USA & Texas Tech University & 10 & Water treatment/separation \\
6 & Chao Lang & USA & Pennsylvania State University & 9 & Material science \\
7 & Aleksandr Noy & USA & Lawrence Livermore National Laboratory & 8 & Material science \\
8 & Huaqiang Zeng & Singapore & A-Star, Institute of Bioengineering and Nanotechnology & 8 & Biochemistry \\
9 & Junli Hou & China & Fudan University & 5 & Material science \\
10 & Menachem Elimelech & USA & Yale University & 5 & Environmental science \\
\hline
\end{tabular}


suggest that future research and development on biomimetic membranes based on the use of proteins will focus on our ability to synthesize and stabilize proteins (or peptides) in sufficient quantities to achieve high membrane density while achieving scalability. For the artificial water channels, optimizing selectivity, self-assembly properties, and stability will constitute the main challenges to be addressed.

Received: 18 April 2021; Accepted: 7 July 2021; Published online: 22 July 2021

\section{REFERENCES}

1. Burek, P. et al. Water Futures and Solution-Fast Track Initiative (Final Report) (IIASA Working Paper, 2016).

2. UN. The United Nations World Water Development Report. World Water Assessment Programme (Nations Unies) http://www.unwater.org/publications/ world-water-development-report-2018/ (2018).

3. Anim, D. O. \& Ofori-Asenso, R. Water scarcity and COVID-19 in sub-Saharan Africa. J. Infect. 81, e108-e109 (2020).

4. Boretti, A. \& Rosa, L. Reassessing the projections of the World Water Development Report.npj Clean Water 2, 15 (2019).

5. Drechsel, P., Mahjoub, O. \& Keraita, B. in Wastewater: Economic Asset in an Urbanizing World (eds Pay Drechsel, Mansoor Qadir, \& Dennis Wichelns) 75-92 (Springer, 2015).

6. Wilkinson, J. L., Hooda, P. S., Barker, J., Barton, S. \& Swinden, J. Ecotoxic pharmaceuticals, personal care products, and other emerging contaminants: a review of environmental, receptor-mediated, developmental, and epigenetic toxicity with discussion of proposed toxicity to humans. Crit. Rev. Environ. Sci. Technol. 46, 336-381 (2016).

7. Hintemann, T., Schneider, C., Schöler, H. F. \& Schneider, R. J. Field study using two immunoassays for the determination of estradiol and ethinylestradiol in the aquatic environment. Water Res. 40, 2287-2294 (2006).

8. Mills, M. R. et al. Removal of ecotoxicity of 17 a-ethinylestradiol using TAML/ peroxide water treatment. Sci. Rep. 5, 10511 (2015).

9. Brian Jayne, V. et al. Accurate prediction of the response of freshwater fish to a mixture of estrogenic chemicals. Environ. Health Perspect. 113, 721-728 (2005).

10. Cooney, C. M. Study detects trace levels of pharmaceuticals in U.S. drinking water. Environ. Sci. Technol. 43, 551-551 (2009).

11. Benotti, M. J. et al. Pharmaceuticals and endocrine disrupting compounds in U.S. drinking water. Environ. Sci. Technol. 43, 597-603 (2009).

12. Voicu, S. I. \& Sandru, M. in Handbook of Bioceramics and Biocomposites (ed Iulian Vasile Antoniac) 407-429 (Springer International Publishing, 2016).

13. Shenvi, S. S., Isloor, A. M. \& Ismail, A. F. A review on RO membrane technology: developments and challenges. Desalination 368, 10-26 (2015).

14. Fuwad, A., Ryu, H., Malmstadt, N., Kim, S. M. \& Jeon, T. J. Biomimetic membranes as potential tools for water purification: preceding and future avenues. Desalination 458, 97-115 (2019).

15. Werber, J. R., Osuji, C. O. \& Elimelech, M. Materials for next-generation desalination and water purification membranes.Nat. Rev. Mater. 1, 16018 (2016).

16. Tang, C., Wang, Z., Petrinić, I., Fane, A. G. \& Hélix-Nielsen, C. Biomimetic aquaporin membranes coming of age. Desalination 368, 89-105 (2015).

17. Chemistry RSo. Artificial Water Channels Faraday Discussion (Royal Society of Chemistry, 2018) https://www.rsc.org/events/detail/26212/artificial-waterchannels-faraday-discussion.

18. Tu, Y.-M. et al. Prospective applications of nanometer-scale pore size biomimetic and bioinspired membranes. J. Membr. Sci. 620, 118968 (2021).

19. Huang, L.-B., Vincenzo, Di. M., Li, Y. \& Barboiu, M. Artificial water channels: towards biomimetic membranes for desalination. Chem.-A Eur. J. 27, 2224-2239 (2021).

20. Mavukkandy, M. O. et al. Thin film deposition techniques for polymeric membranes-a review. J. Membr. Sci. 610, 118258 (2020).

21. Kumar, N., Goel, G., Hawi, S. \& Goel, S. Nature inspired materials: emerging trends and prospects NPG Asia Mater. (in the press).

22. Mueller, P., Rudin, D. O., Ti Tien, H. \& Wescott, W. C. Reconstitution of cell membrane structure in vitro and its transformation into an excitable system. Nature 194, 979-980 (1962).

23. Tsukube, H., Takagi, K., Higashiyama, T., Iwachido, T. \& Hayama, N. Biomimetic application of natural valinomycin and nonactine ionophores to artificial transport of amino acid salts. Bull. Chem. Soc. Jpn. 59, 2021-2022 (1986).
24. Tsukube, H., Takagi, K., Higashiyama, T., Iwachido, T. \& Hayama, N. Biomimetic transport of unusual metal cations and amino acid ester salts mediated by monensin and lasalocid A. J. Chem. Soc., Chem. Commun. 6, 448-449 (1986).

25. Takahashi, F. Energy theory series 10: biomimetic conversion of solar energy into electricity. Petrotech. 1, 1053-1058 (1978).

26. Bhardwaj, R., Pan, R. L. \& Gross, E. L. Solar energy conversion by chloroplast photoelectrochemical cells. Nature 289, 396-398 (1981).

27. Tang, C. W. \& Albrecht, A. C. Chlorophyll-a photovoltaic cells. Nature 254, 507-509 (1975).

28. Tributsch, H. Application of electrochemical kinetics to photosynthesis and oxidative phosphorylation: the redox element hypothesis and the principle of parametric energy coupling. J. Bioenerg. 2, 249-273 (1971).

29. Preston, G. M., Carroll, T. P., Guggino, W. B. \& Agre, P. Appearance of water channels in Xenopus oocytes expressing red cell CHIP28. Protein Sci. 256, 385-387 (1992).

30. King, L. S., Kozono, D. \& Agre, P. From structure to disease: the evolving tale of aquaporin biology. Nat. Rev. Mol. Cell Biol. 5, 687-698 (2004).

31. Agre, P. Aquaporin Water channels (Nobel Lecture). Angew. Chem. Int. Ed. 43, 4278-4290 (2004).

32. Tu, Y. M. et al. Rapid fabrication of precise high-throughput filters from membrane protein nanosheets. Nat. Mater. 19, 347-354 (2020).

33. Ali, A. et al. A review of membrane crystallization, forward osmosis and membrane capacitive deionization for liquid mining. Resour., Conserv. Recycling 168, 105273 (2021).

34. Aquaporin. Water Made by Nature: Annual Report https://aquaporin.com/wpcontent/uploads/2019/09/Aquaporin-Annual-Report-2018.pdf (2018).

35. Hélix-Nielsen, C. Biomimetic membranes as a technology platform: challenges and opportunities. Membranes 8, 44 (2018).

36. Ryu, $\mathrm{H}$. et al. Biomimetic membranes with transmembrane proteins: state-ofthe-art in transmembrane protein applications. Int. J. Mol. Sci. 20, 1437 (2019).

37. Abdelrasoul, A., Doan, H., Lohi, A. \& Cheng, C. H. Aquaporin-based biomimetic and bioinspired membranes for new frontiers in sustainable water treatment technology: approaches and challenges. Polym. Sci. Ser. A 60, 429-450 (2018).

38. Porter, C. J., Werber, J. R., Zhong, M., Wilson, C. J. \& Elimelech, M. Pathways and challenges for biomimetic desalination membranes with sub-nanometer channels. ACS Nano 14, 10894-10916 (2020).

39. Kumar, M., Grzelakowski, M., Zilles, J., Clark, M. \& Meier, W. Highly permeable polymeric membranes based on the incorporation of the functional water channel protein Aquaporin Z. Proc. Natl Acad. Sci. 104, 20719 (2007).

40. Zhou, D., Zhou, H., Zhou, S. \& Tong, Y. W. Investigating the mechanisms of AquaporinZ reconstitution through polymeric vesicle composition for a biomimetic membrane. Polymers 12, 1944 (2020).

41. Hansen, J. S. et al. Interaction between sodium dodecyl sulfate and membrane reconstituted aquaporins: a comparative study of spinach SoPIP2;1 and E. coli AqpZ.Biochim. et Biophys. Acta (BBA)—Biomembranes 1808, 2600-2607 (2011).

42. Stillwell, W. in An Introduction to Biological Membranes (ed William Stillwell) 305 -337 (Elsevier, 2013).

43. Kozono, D., Yasui, M., King, L. S. \& Agre, P. Aquaporin water channels: atomic structure molecular dynamics meet clinical medicine. J. Clin. Investig. 109, 1395-1399 (2002).

44. Shen, Y. X., Saboe, P. O., Sines, I. T., Erbakan, M. \& Kumar, M. Biomimetic membranes: a review. J. Membr. Sci. 454, 359-381 (2014).

45. Sam, A., K, V. P. \& Sathian, S. P. Water flow in carbon nanotubes: the role of tube chirality. Phys. Chem. Chem. Phys. 21, 6566-6573 (2019).

46. Julie R., Kirt C. (eds) International Space Station Benefits for Humanity (NASA, 2018).

47. Hill, T. R. \& Taylor, B. W. Use of aquaporins to achieve needed water purity on the International Space Station for the Extravehicular Mobility Unit Space Suit System. In 42nd International Conference on Environmental Systems. 15-19 (American Institute of Aeronautics and Astronautics, San Diego, CA, USA, 2012).

48. Perry, M. et al. Challenges in commercializing biomimetic membranes. Membranes 5, 685-701 (2015).

49. Song, W. \& Kumar, M. Artificial water channels: toward and beyond desalination. Curr. Opin. Chem. Eng. 25, 9-17 (2019).

50. Hummer, G., Rasaiah, J. C. \& Noworyta, J. P. Water conduction through the hydrophobic channel of a carbon nanotube. Nature 414, 188-190 (2001).

51. Holt, J. K. et al. Fast mass transport through sub-2-nanometer carbon nanotubes. Science 312, 1034 (2006).

52. Tunuguntla, R. H. et al. Enhanced water permeability and tunable ion selectivity in subnanometer carbon nanotube porins. Science 357, 792 (2017).

53. Corry, B. Designing carbon nanotube membranes for efficient water desalination. J. Phys. Chem. B 112, 1427-1434 (2008).

54. Percec, V. et al. Self-assembly of amphiphilic dendritic dipeptides into helical pores. Nature 430, 764-768 (2004). 
55. LeDuc, Y. et al. Imidazole-quartet water and proton dipolar channels. Angew. Chem. Int. Ed. 50, 11366-11372 (2011).

56. Sun, Z., Kocsis, I., Li, Y., Legrand, Y.-M. \& Barboiu, M. Imidazole derivatives as artificial water channel building-blocks: structural design influence on water permeability. Faraday Discuss. 209, 113-124 (2018).

57. Di Vincenzo, M. et al. Biomimetic artificial water channel membranes for enhanced desalination. Nat. Nanotechnol. 16, 190-196 (2020).

58. Zhou, X. et al. Self-assembling subnanometer pores with unusual mass-transport properties. Nat. Commun. 3, 949 (2012).

59. Roy, A. et al. Foldamer-based ultrapermeable and highly selective artificial water channels that exclude protons. Nat. Nanotechnol. https://doi.org/10.1038/ s41565-021-00915-2 (2021).

60. Hu, X. B., Chen, Z., Tang, G., Hou, J. L. \& Li, Z. T. Single-molecular artificial transmembrane water channels. J. Am. Chem. Soc. 134, 8384-8387 (2012).

61. Shen, J. et al. Aquafoldmer-based aquaporin-like synthetic water channel. J. Am. Chem. Soc. 142, 10050-10058 (2020).

62. Epsztein, R., DuChanois, R. M., Ritt, C. L., Noy, A. \& Elimelech, M. Towards singlespecies selectivity of membranes with subnanometre pores. Nat. Nanotechnol. 15, 426-436 (2020)

63. Huang, L.-B. et al. Hydroxy channels-adaptive pathways for selective water cluster permeation. J. Am. Chem. Soc. 143, 4224-4233 (2021).

64. Abaie, E., Xu, L. \& Shen, Y.-X. Bioinspired and biomimetic membranes for water purification and chemical separation: a review. Front. Environ. Sci. Eng. 15, 124 (2021).

65. Shen, J., Liu, G., Han, Y. \& Jin, W. Artificial channels for confined mass transport at the sub-nanometre scale.Nat. Rev. Mater. 6, 294-312 (2021).

66. Ang, W. L., Wahab Mohammad, A., Johnson, D. \& Hilal, N. Forward osmosis research trends in desalination and wastewater treatment: a review of research trends over the past decade.J. Water Process Eng. 31, 100886 (2019).

67. HEFCE. Higher Education Funding Council for England http://www.hefce.ac.uk/ Research/ref (2009).

68. Pritchard, A. Statistical bibliography or bibliometrics? J. Documentation 25 348-349 (1969).

69. Cobo, M. J., López-Herrera, A. G., Herrera-Viedma, E. \& Herrera, F. Science mapping software tools: review, analysis, and cooperative study among tools. J. Am. Soc. Inf. Sci. Technol. 62, 1382-1402 (2011).

70. van Eck, N. J. \& Waltman, L. Software survey: VOSviewer, a computer program for bibliometric mapping. Scientometrics 84, 523-538 (2010).

71. Youngblood, M. \& Lahti, D. A. Bibliometric analysis of the interdisciplinary field of cultural evolution. Palgrave Commun. 4, 120 (2018).

72. Newman, M. E. J. Fast algorithm for detecting community structure in networks. Phys. Rev. E 69, 066133 (2004).

73. van Eck, N. J. \& Waltman, L. in Measuring Scholarly Impact: Methods and Practice (eds Ying Ding, Ronald Rousseau, \& Dietmar Wolfram) 285-320 (Springer International Publishing, 2014).

74. Aria, M. \& Cuccurullo, C. bibliometrix: an R-tool for comprehensive science mapping analysis. J. Informetr. 11, 959-975 (2017).

75. Murata, K. et al. Structural determinants of water permeation through aquaporin-1. Nature 407, 599-605 (2000)

76. Montemagno, C. D., Schmidt, J. J. \& Tozzi, S. P. Biomimetic membranes. USA patent US20040049230A1 (2004).

77. Jensen, P. H., Keller, D. \& Nielsen, C. H. Membrane for filtering of water. USA patent US7857978B2 (2006).

78. Nielsen, C. H. Biomimetic membranes for sensor and separation applications Anal. Bioanal. Chem. 395, 697-718 (2009).

79. Barboiu, M. in Bio-inorganic Hybrid Nanomaterials: Strategies, Syntheses, Characterization, and Applications 313-337 (John Wiley and Sons, 2008).

80. HTI. State of the Art Automated Forward Osmosis Membrane Manufacturing Facility http://htiwater.com/company/hti_history.html (2021).

81. Zhao, Y. et al. Synthesis of robust and high-performance aquaporin-based biomimetic membranes by interfacial polymerization-membrane preparation and RO performance characterization. J. Membr. Sci. 423-424, 422-428 (2012).

82. Aquaporin. Aquaporin in New Partnership for Improved Water Treatment in India https://aquaporin.com/new-partnership-with-focus-on-purification-andrecycling-of-water-in-india/ (2019).

83. Aquaporin. Darco collaborates with Aquaporin on FO project. Pump Industry Analyst 2016, 4 (2016)

84. Aquaporin. Aquaporin's annual report highlights results and milestones for 2018. Membr. Techol. 2019, 4 (2019)

85. O. W. D. Our World in Data https://ourworldindata.org/water-use-stress (2021).

86. World Bank. Open Data https://data.worldbank.org/indicator/SP.POP.TOTL (2021).

87. Liao, Y., Loh, C.-H., Tian, M., Wang, R. \& Fane, A. G. Progress in electrospun polymeric nanofibrous membranes for water treatment: fabrication, modification, and applications. Prog. Polym. Sci. 77, 69-94 (2018).
88. Gravelle, S. et al. Optimizing water permeability through the hourglass shape of aquaporins. Proc. Natl Acad. Sci. USA. 110, 16367-16372 (2013).

89. Zhong, P. S., Chung, T. S., Jeyaseelan, K. \& Armugam, A. Aquaporin-embedded biomimetic membranes for nanofiltration. J. Membr. Sci. 407-408, 27-33 (2012).

90. $\mathrm{Li}, \mathrm{X}$. et al. Preparation of high performance nanofiltration (NF) membranes incorporated with aquaporin Z. J. Membr. Sci. 450, 181-188 (2014).

91. Xie, W. et al. An aquaporin-based vesicle-embedded polymeric membrane for low energy water filtration. J. Mater. Chem. A 1, 7592-7600 (2013).

92. Li, X. et al. Nature gives the best solution for desalination: aquaporin-based hollow fiber composite membrane with superior performance. J. Membr. Sci. 494, 68-77 (2015).

93. Wang, M. et al. Layer-by-layer assembly of aquaporin z-incorporated biomimetic membranes for water purification. Environ. Sci. Technol. 49, 3761-3768 (2015).

94. Li, X. et al. Preparation of supported lipid membranes for aquaporin Z incorporation. Colloids Surf. B 94, 333-340 (2012).

95. Qi, S. et al. Aquaporin-based biomimetic reverse osmosis membranes: stability and long term performance. J. Membr. Sci. 508, 94-103 (2016).

96. Duong, P. H. H. et al. Planar biomimetic aquaporin-incorporated triblock copolymer membranes on porous alumina supports for nanofiltration. J. Membr. Sci. 409-410, 34-43 (2012).

97. Si, W. et al. Selective artificial transmembrane channels for protons by formation of water wires. Angew. Chem. Int. Ed. 50, 12564-12568 (2011).

98. Nunes, S. P. et al. Ultraporous films with uniform nanochannels by block copolymer micelles assembly. Macromolecules 43, 8079-8085 (2010).

99. Henmi, M. et al. Self-organized liquid-crystalline nanostructured membranes for water treatment: selective permeation of ions. Adv. Mater. 24, 2238-2241 (2012).

100. Majumder, M., Chopra, N. \& Hinds, B. J. Mass transport through carbon nanotube membranes in three different regimes: ionic diffusion and gas and liquid flow. ACS Nano 5, 3867-3877 (2011).

101. Shen, Y.-x et al. Highly permeable artificial water channels that can selfassemble into two-dimensional arrays. Proc. Natl Acad. Sci. USA 112, 9810 (2015).

102. Yang, Y. et al. Control performance and biomembrane disturbance of carbon nanotube artificial water channels by nitrogen-doping. ACS Nano 4, 5755-5762 (2010).

103. Radha, B. et al. Molecular transport through capillaries made with atomic-scale precision. Nature 538, 222-225 (2016).

104. Gong, B. et al. Creating nanocavities of tunable sizes: hollow helices. Proc. Natl Acad. Sci. USA 99, 11583 (2002).

105. Sackmann, E. Supported membranes: scientific and practical applications. Sci 271, 43 (1996).

106. Pendergast, M. M. \& Hoek, E. M. V. A review of water treatment membrane nanotechnologies. Energy Environ. Sci. 4, 1946-1971 (2011).

107. Kita-Tokarczyk, K., Grumelard, J., Haefele, T. \& Meier, W. Block copolymer vesicles - using concepts from polymer chemistry to mimic biomembranes. Polymer 46, 3540-3563 (2005)

108. Tang, C. Y., Zhao, Y., Wang, R., Hélix-Nielsen, C. \& Fane, A. G. Desalination by biomimetic aquaporin membranes: review of status and prospects. Desalination 308, 34-40 (2013).

109. Taubert, A., Napoli, A. \& Meier, W. Self-assembly of reactive amphiphilic block copolymers as mimetics for biological membranes. Curr. Opin. Chem. Biol. 8, 598-603 (2004).

110. Zhao, J. et al. Biomimetic and bioinspired membranes: preparation and application. Prog. Polym. Sci. 39, 1668-1720 (2014).

111. Le Meins, J. F., Schatz, C., Lecommandoux, S. \& Sandre, O. Hybrid polymer/lipid vesicles: state of the art and future perspectives. Mater. Today 16, 397-402 (2013).

112. Kowalczyk, S. W., Blosser, T. R. \& Dekker, C. Biomimetic nanopores: learning from and about nature. Trends Biotechnol. 29, 607-614 (2011).

113. Mecke, A., Dittrich, C. \& Meier, W. Biomimetic membranes designed from amphiphilic block copolymers. Soft Matter 2, 751-759 (2006).

114. Barboiu, M. \& Gilles, A. From natural to bioassisted and biomimetic artificial water channel systems. Acc. Chem. Res. 46, 2814-2823 (2013).

115. Wang, Y. N., Goh, K., Li, X., Setiawan, L. \& Wang, R. Membranes and processes for forward osmosis-based desalination: recent advances and future prospects. Desalination 434, 81-99 (2018).

116. Giwa, A. et al. Biomimetic membranes: a critical review of recent progress. Desalination 420, 403-424 (2017).

117. Hinds, B. Dramatic transport properties of carbon nanotube membranes for a robust protein channel mimetic platform. Curr. Opin. Solid State Mater. Sci. 16, 1-9 (2012).

118. Habel, J. et al. Aquaporin-based biomimetic polymeric membranes: approaches and challenges. Membranes 5, 307-351 (2015).

119. Song, W., Lang, C., Shen, Y. X. \& Kumar, M. in Annual Review of Materials Research Vol. 48, 57-82 (Annual Reviews Inc, 2018) 
120. Kocsis, I., Sun, Z., Legrand, Y. M. \& Barboiu, M. Artificial water channelsdeconvolution of natural aquaporins through synthetic design. npj Clean Water 1, 13 (2018).

121. Garni, M. et al. Polymer membranes as templates for bio-applications ranging from artificial cells to active surfaces. Eur. Polym. J. 112, 346-364 (2019).

122. Wagh, P. \& Escobar, I. C. Biomimetic and bioinspired membranes for water purification: a critical review and future directions. Environ. Prog. Sustainable Energy 38, e13215 (2019).

123. Puiggalí-Jou, A., Del Valle, L. J. \& Alemán, C. Biomimetic hybrid membranes: incorporation of transport proteins/peptides into polymer supports. Soft Matter 15, 2722-2736 (2019).

124. Zhang, D. \& Wang, Y. Functional protein-based bioinspired nanomaterials: from coupled proteins, synthetic approaches, nanostructures to applications. Int. J. Mol. Sci. 20, 3054 (2019).

125. Chimisso, V., Maffeis, V., Hürlimann, D., Palivan, C. G. \& Meier, W. Self-assembled polymeric membranes and nanoassemblies on surfaces: preparation, characterization, and current applications. Macromol. Biosci. 20, 1900257 (2020).

126. Nabeel, F. et al. Bio-inspired supramolecular membranes: a pathway to separation and purification of emerging pollutants. Sep. Purif. Rev. 49, 20-36 (2020).

\section{ACKNOWLEDGEMENTS}

All authors gratefully acknowledge the support provided by the UKRI via Grants No.: EP/ L016567/1, EP/S013652/1, EP/T001100/1, EP/S036180/1, and EP/T024607/1, as well as the GCRF/ EPSRC, supported SUNRISE programme EP/P032591/1. Additionally, support received from H2020 (Cost Actions (CA18125, CA18224, CA17136, and CA16235) and EURAMET EMPIR A185 (2018)), Royal Academy of Engineering Grant No. IAPP18-19\295 (Indo-UK partnership), Grant No. TSP1332 (South Africa- UK partnership), Grant No. EXPP2021 \1\277 (Pandemic preparedness) and Royal Society's Newton Fellowship award NIF\R1\191571 are also gratefully acknowledged. CLHE acknowledges support from the NEPWAT project funded by the NovoNordisk Foundation Grant No. NNF18OC0034918. We also acknowledge financial support from the European Regional Development Funds (ERDF) sponsored $\mathrm{A} 2 \mathrm{i}$ project as well as the feasibility study awarded by the EPSRC TFIN + (EP/N026402/1) to LSBU. Wherever applicable, the work made use of Isambard Bristol, UK supercomputing service accessed by Resource Allocation Panel (RAP) grant as well as ARCHER resources (Project e648).

\section{AUTHOR CONTRIBUTIONS}

G.G.: conceptualization, methodology, experimentation, writing-original draft, writing-review, and editing. C.H.-N.: methodology, formal analysis, writing-original draft, writing-review, and editing. H.M.U.: writing-review, and editing. S.G.: methodology, investigation, writing-review, and editing.

\section{COMPETING INTERESTS}

The authors declare no competing interests.

\section{ADDITIONAL INFORMATION}

Correspondence and requests for materials should be addressed to G.G.

Reprints and permission information is available at http://www.nature.com/ reprints

Publisher's note Springer Nature remains neutral with regard to jurisdictional claims in published maps and institutional affiliations.

Open Access This article is licensed under a Creative Commons Attribution 4.0 International License, which permits use, sharing, adaptation, distribution and reproduction in any medium or format, as long as you give appropriate credit to the original author(s) and the source, provide a link to the Creative Commons license, and indicate if changes were made. The images or other third party material in this article are included in the article's Creative Commons license, unless indicated otherwise in a credit line to the material. If material is not included in the article's Creative Commons license and your intended use is not permitted by statutory regulation or exceeds the permitted use, you will need to obtain permission directly from the copyright holder. To view a copy of this license, visit http://creativecommons. org/licenses/by/4.0/.

(c) The Author(s) 2021 